\title{
EQUIPOS DIRECTIVOS MUNICIPALES EFICACES PARA AVANZAR HACIA UN GOBIERNO COMUNAL: ESTUDIO DE CASO DEL MUNICIPIO DE CHILLÁN
}

\author{
EFFECTIVE MUNICIPAL MANAGEMENT TEAMS TO MOVE TOWARDS A COMMUNAL \\ GOVERNMENT: A CASE STUDY OF THE MUNICIPALITY OF CHILLÁN
}

\author{
Zoraya Martínez S.* y Jonathan Fuentes P.**
}

\begin{abstract}
Resumen
El presente artículo se enmarca en el estudio de la eficacia de los equipos directivos al interior de la municipalidad de Chillan, región de Ñuble, Chile. El objetivo fue determinar limitantes, desafíos y oportunidades en la construcción de un equipo directivo municipal eficaz, a fin de asegurar la solución de los problemas de su comunidad local, desde una perspectiva de la lógica interna municipal. La investigación se posiciona desde el paradigma interpretativo, la metodología fue cualitativa. El estudio utilizó como técnica principal de recogida de información la entrevista semiestructurada, la que fue aplicada a los directivos de la municipalidad de Chillán, a las alcaldesas de Providencia y Peñalolén y expertos del mundo académico y de la administración pública. Una segunda técnica fue un focus group trabajada con el equipo directivo, con el objeto de reforzar conceptos claves asociados a las categorías del estudio. Finalmente se desarrolló análisis documentación sobre expedientes internos de la Municipalidad, reglamento de funcionamiento interno, revisión de página web municipal y Estatuto Administrativo de los funcionarios municipales. El análisis de la información recogida fue en base al uso de la técnica análisis de contenido.
\end{abstract}

Palabras clave: Administración Municipal, Gobierno Comunal, Equipos Directivos Eficaces, Desarrollo Local y Territorial, Capital Social Interno.

\begin{abstract}
This article is framed in the study of the effectiveness of management teams within a municipality of Chillan, Nuble region, Chile. The objective was to determine limitations, challenges and opportunities in the construction of an effective municipal management team, in order to ensure the solution of the problems of the local community, from the perspective of the internal municipal logic. The research is positioned from the interpretative paradigm, the methodology was qualitative.
\end{abstract}

\footnotetext{
* Asistente Social, Magíster en Política y Gobierno, Magíster en Ciencias Sociales, Jefa Departamento de Vivienda de la Ilustre Municipalidad Chillán, Chillán, Chile, correo zorayamartinez@municipalidadchillan.cl ORCID https://orcid.org/0000-0002-1018-7847

** Trabajador Social, Magíster en Política y Gobierno, Trabajador Social del Liceo Heise Marti, comuna de Parral. correo: jonapsb@gmail.com, ORCID: https://orcid.org/0000-0003-3584-9031.
} 
The study used a semi-structured interview as the main information gathering technique, which was applied to the directors of the municipality of Chillán, the mayors of Providencia and Peñalolén and experts from the academic world and public administration. A second technique was a focus group worked with the management team, in order to reinforce key concepts associated with the categories of the study. Finally, documentation analysis was carried out on internal files of the Municipality, internal operating regulations, review of the municipal web page and Administrative Statute of the municipal employees. The analysis of the information collected was based on the use of the content analysis technique.

Keywords: Municipal Administration, Communal Government, Effective Management Teams, Local and Territorial Development, Internal Social Capital.

Recibido: 12 de enero de 2021 / Aceptado: 14 de abril de 2021

\section{Introducción}

En la realidad social y política de cada comuna del país, las demandas de la población siempre superan con creces las expectativas de sus directivos municipales. Esto es así porque las expectativas ciudadanas esperan respuestas favorables de su municipio, pero éste no cuenta con las capacidades organizativas ni de recursos para resolverlas favorablemente. Es la experiencia cierta de la gran mayoría de las municipalidades de nuestro país.

Los alcaldes han planteado históricamente que la calidad de "administraciones locales" que determina la Ley Orgánica Constitucional de Municipalidades, en sus artículos números 3, 4,5 y 6 , por medio de sus funciones privativas y compartidas, no les permite dar respuesta favorable a todas las demandas de su población. Culpan a la legislación municipal de sus deficiencias. La presente tesis parte del supuesto de que esto no es así; que las limitaciones en la ley también pueden ser concebidas como oportunidades de innovar en la gestión pública municipal, considerando procedimientos y normativa vigente.

Si bien es cierto que la Ley Orgánica Constitucional de Municipalidades 18.695 en su art. $\mathrm{N}^{\circ} 1$, define a las municipalidades como "administraciones locales" y delimita sus áreas de acción e influencia administrativa, no lo es menos, que posibilita un accionar más decisivo e incidente en el plano social, de manera que cada realidad territorial actúe de acuerdo a sus capacidades y a sus propias potencialidades directivas.

Esta lógica es la que determina si una municipalidad actuará siempre como una mera "administración municipal", según el art. $\mathrm{N}^{\circ} 1$ de la Ley Orgánica Constitucional de Municipalidades, o avanzará un paso más adelante para enfrentar sus tareas y responsabilidades como un verdadero "gobierno comunal", esto es, con capacidad de resolver aquellas cuestiones de la vida comunal que exceden o superan la norma legal y que son necesarias de resolver favorablemente para beneficio de sus comunidades. 
El presente trabajo propone observar cómo las municipalidades concebidas como gobiernos comunales, empoderados en sus responsabilidades, que apuesta en sus equipos directivos profesionales capacitados para que conduzcan los procesos de mejora continua en la gestión municipal y logren atender las crecientes demandas de la ciudadanía. Consecuencialmente, entonces, el tema de investigación se referirá a las capacidades directivas de un municipio que lo impulsen a enfrentar con éxito las demandas de su comunidad local, y por tanto su ámbito se enmarca en un territorio comunal específico, que cuenta con un equipo directivo con capacidad de liderazgo, surgido de la conducción legítima de su alcalde, en votación popular democrática y participativa.

Pretendemos investigar, entonces, cómo los equipos directivos de una municipalidad están preparados y capacitados para que su municipio sea capaz de responder a las principales exigencias que la ciudadanía comunal les plantea.

La pregunta principal o directriz de nuestra tesis será entonces: ¿cuáles son las principales limitantes, oportunidades y desafíos que debe enfrentar el cuerpo directivo municipal para dar respuesta eficaz a las demandas de su ciudadanía comunal?

En el ámbito espacial, nuestro estudio se sitúa en una municipalidad específica, la municipalidad de Chillan, Provincia de Nuble, concebida por la legislación como un ente público encargado de atender y resolver los asuntos de su comunidad local.

\subsection{Chile y su desarrollo. La modernización del Estado}

La instauración de la dictadura cívico militar en Chile (1973-1990), supuso una radical transformación de cómo era concebido el Estado y su función en el bienestar de la población. De acuerdo a lo planteado por Doña (2006), la privatización de los sistemas de pensiones, salud y de la mayoría de las empresas estatales, junto con el traspaso a los municipios de la función social de la salud y la educación, implicaron plasmar en la administración estatal el modelo neoliberal bajo la estructura estatal autoritaria, como bien señala Cádiz (2005 s/p), la cual indica que en esta época (el):

"Estado se reestructura en el ámbito productivo, financiero, económico, social y político, desdiciéndose de su rol histórico como Estado-bienestar, para introducir al país en una lógica puramente mercantil, a través de la dominación coercitiva de todo movimiento social y político que implicará peligro para la consecución de sus fines (...) Así, a través del miedo y la represión se pudo fundar un Estado al servicio del capital neoliberal como única posibilidad de desarrollo (Cadiz, 2005)".

Esta situación para este estudio no se pretende profundizar, no obstante mencionar que esta situación se vivió hasta marzo de 1990. Es así como, con el retorno a los gobiernos nacionales civiles en los últimos 25 años, nuestro país ha cambiado considerablemente en cuanto a su desarrollo económico y social, demográfico y en lo político. La sociedad chilena ha avanzado en dirección a la búsqueda de mayores libertades y oportunidades, así como en mayor igualdad en todos los ámbitos de la vida social. De acuerdo a lo planteado 
por Williamson (2013), en Chile se ha consensuado la necesidad de contar con un Estado moderno, fuerte, que regule, pero que a la vez no llegue a asfixiar la actividad privada, en donde se gestione de forma adecuada los recursos, cuidando a la vez a los sectores más vulnerables de la sociedad.

\subsection{La modernización del Estado: en búsqueda de respuestas a la creciente complejidad social}

Los antecedentes antes descritos implican, el intento por parte de los organismos públicos de adaptarse a estos cambios socioeconómicos y demográficos. Los cambios traen consigo nuevas necesidades y nuevas interrogantes que se deben tratar de solucionar, dependiendo en gran medida de la agenda gubernamental y de la agenda pública existente en determinado momento.

Todo lo anterior ha significado un avance en la modernización de nuestras instituciones públicas y privadas que acrecientan su complejidad institucional y exigen mejores niveles de organización para la consecución de mayores objetivos sociales. A continuación, y tomando también como referencia lo planteado por Ramírez (2001), Tomassini y Armijo (2002), Doña (2005), Cunill (2009) Rogers y Guzmán (2015), expondremos los procesos modernizadores más relevantes desde el gobierno del Presidente Patricio Aylwin hasta el gobierno del Presidente Sebastián Piñera Echeñique.

Tabla $N^{\circ} 1$ : Procesos modernizadores en cada período presidencial desde 1990 a 2014.

\begin{tabular}{|l|l|}
\hline $\begin{array}{l}\text { Períodos } \\
\text { presidenciales }\end{array}$ & Procesos modernizadores en cada período presidencial \\
\hline $\begin{array}{l}\text { Pdte. Patricio } \\
\text { Aylwin Azócar } \\
\text { (1990-1994). }\end{array}$ & $\begin{array}{l}\text { Democratización de los gobiernos municipales y se formalizan las } \\
\text { asociaciones de funcionarios. }\end{array}$ \\
$>\begin{array}{l}\text { Se establecen procesos modernizadores en Tesorería General de la } \\
\text { República, Servicio de Impuestos Internos, FONASA, Registro Civil, } \\
\text { entre otros. }\end{array}$ & $\begin{array}{l}\text { Modernización de la institucionalidad, mediante la creación del } \\
\text { Ministerio de Planificación y Cooperación, el Servicio Nacional de la } \\
\text { Mujer (SERNAM), el Fondo Nacional e Inversión Social (FOSIS), el } \\
\text { Instituto Nacional de la Juventud (INJUV), entre otros }\end{array}$ \\
\hline $\begin{array}{l}\text { Pdte. Eduardo Frei } \\
\text { Ruíz-Tagle (1994- } \\
\text { 2000). }\end{array}$ & $\begin{array}{l}\text { Desarrollo de agenda para la modernización de la gestión pública, } \\
\text { orientándola al servicio de los ciudadanos incorporando conceptos de } \\
\text { la Nueva Gerencia Publica bajo el slogan “El Estado como agente de } \\
\text { Progreso", cuyas medidas fueron. a) liderazgo organizacional, b) } \\
\text { preocupación por resultados, c) transparencia y eficiencia, d) calidad } \\
\text { del servicio, e) participación ciudadana y, f) uso de las tecnologías de }\end{array}$ \\
\hline
\end{tabular}




\begin{tabular}{|c|c|}
\hline & $\begin{array}{l}\text { la información. } \\
\text { Las reformas más relevantes en este periodo fueron: a) Reforma } \\
\text { Procesal Penal, b) Reforma de concesiones de obras públicas y c) } \\
\text { Reforma Educacional. }\end{array}$ \\
\hline $\begin{array}{l}\text { Pdte. } \quad \text { Ricardo } \\
\text { Lagos } \quad \text { Escobar } \\
(2000-2006)\end{array}$ & $\begin{array}{l}\text { Se continúa con el proceso modernizador del gobierno anterior, } \\
\text { mediante el Proyecto de Reforma y Modernización del Estado, cuyos } \\
\text { principios orientadores fueron: un estado más democrático, } \\
\text { participativo, transparente, unitario, descentralizado, solidario, } \\
\text { eficiente, eficaz y subsidiario. } \\
>\text { Se crea el Sistema de Alta Dirección Pública. } \\
>\text { Se moderniza el sistema de compras públicas, Ley } 19.886 . \\
>\text { En la mayoría de los servicios públicos chilenos, se promueve el } \\
\text { gobierno electrónico. } \\
>\text { Se inicia el Programa Chile Solidario y el Plan Auge. }\end{array}$ \\
\hline $\begin{array}{l}\text { Pdta. } \quad \text { Michelle } \\
\text { Bachelet } \quad \text { Jeria } \\
(2006-2010) \text {. }\end{array}$ & $\begin{array}{l}\text { Se promulga la Ley de Transparencia en todos los servicios públicos, } \\
\text { y se crea el Consejo para la transparencia en la gestión pública. } \\
\\
\text { Reforma previsional. El pilar solidario. }\end{array}$ \\
\hline $\begin{array}{l}\text { Pdte. Sebastián } \\
\text { Piñera Echeñique } \\
(2010-2014) \text {. }\end{array}$ & $\begin{array}{l}\text { Se crea Chile Atiende, programa de información a la comunidad. } \\
>\text { Se crea Ministerio de Desarrollo Social, ex MIDEPLAN. } \\
>\text { Promoción de Desarrollo Regional. } \\
>\text { Entrega de Vouchers a la ciudadanía para: a) la reconstrucción post- } \\
\text { terremoto, b) Construcción de viviendas sociales y c) Capacitación } \\
>\text { En materia social, la creación de la nueva ficha de protección social y } \\
\text { la conceptualización de Ingreso Ético Familiar. }\end{array}$ \\
\hline
\end{tabular}

Fuente: elaboración propia, basado en lo planteado por Ramírez (2001), Tomassini y Armijo (2002), Cunill (2009) Rogers y Guzmán (2015), Doña (2006).

La perspectiva antes mencionada (modernización de las instituciones) otorga herramientas que aportan un marco valórico que permite influir en un contexto social con transformaciones cada vez más rápidas y de constante aumento de demandas. El enfoque en 
la articulación de las políticas públicas y servicios a la comunidad está dado por los principios orientadores del nuevo servicio público.

\subsection{El Nuevo Servicio Público (NSP)}

El nuevo servicio público se enmarca también en lo referido a mecanismos post burocráticos de gestión pública, posterior a la concepción inicial de nueva gestión pública. Los aspectos esenciales en este concepto dicen relación con la transformación de la interacción entre gobierno y ciudadanos, brindando con ello mejores relaciones sociales con amplia información e impulsando transformaciones (Mariñez, 2013). El impulso de esta nueva forma de relación ciudadana con los servicios públicos gubernamentales implica el desarrollo de un concepto de ciudadanía involucrada activamente en sus procesos de desarrollo. En ese sentido, el Nuevo Servicio Público redirecciona el propósito de la entrega de un servicio por parte de la agencia gubernamental a través de la colaboración entre actores gubernamentales y la ciudadanía empoderada, contexto relacional en el cual se crean las instancias necesarias para definir de mejor forma los problemas públicos y las estrategias que en conjunto se podrían llevar a cabo para la solución de éstos.

Es de esta forma y siguiendo lo planteado por Mariñez (2013) que el Nuevo Servicio Público tiene su origen en la participación e involucramiento de los grupos sociales, cambiando incluso el propósito del funcionario público desde el implementador y administrador de programas preexistentes a facilitador de la participación y colaboración entre los ciudadanos.

Citando a Denhardt y Denhardt (2000, 2003, 2011), Pereira y Jaraíz (2015) proponen siete principios que guían la construcción de un Nuevo Servicio Público, el cual se muestra en la siguiente tabla:

Tabla $\mathrm{N}^{\circ}$ 2: Principios y características de enfoque post burocrático Nuevo Servicio Público.

\begin{tabular}{|l|l|}
\hline $\begin{array}{l}\text { Principios de enfoque post } \\
\text { burocrático de NSP }\end{array}$ & $\begin{array}{l}\text { Características de enfoques post burocráticos de } \\
\text { NSP }\end{array}$ \\
\hline $\begin{array}{l}\text { 1.- Servir a los ciudadanos, no a } \\
\text { clientes o consumidores }\end{array}$ & $\begin{array}{l}\text { Los funcionarios públicos construyen lazos de } \\
\text { confianza y colaboración con los ciudadanos, en vez } \\
\text { de una relación determinada por las demandas o } \\
\text { necesidades de consumidores, consolidando interés } \\
\text { general como la sumatoria de intereses individuales. }\end{array}$ \\
\hline $\begin{array}{l}\text { 2.- Búsqueda de interés público } \\
\text { como objetivo }\end{array}$ & $\begin{array}{l}\text { El interés público se constituye mediante una } \\
\text { construcción colectiva ciudadana, para los cuales los } \\
\text { funcionarios públicos deben trabajar en su búsqueda. }\end{array}$ \\
\hline $\begin{array}{l}\text { 3.- Defender los valores } \\
\text { implícitos de ciudadanía y } \\
\text { servicio público por encima del }\end{array}$ & $\begin{array}{l}\text { Los funcionarios públicos también son ciudadanos, } \\
\text { que deben contribuir en la sociedad. }\end{array}$ \\
\hline
\end{tabular}




\begin{tabular}{|c|c|}
\hline espíritu empresarial & \\
\hline $\begin{array}{l}\text { 4.- Pensar estratégicamente y } \\
\text { actuar democráticamente }\end{array}$ & $\begin{array}{l}\text { Las políticas y las necesidades de los programas } \\
\text { públicos se constituyen eficazmente por medio de la } \\
\text { relación colaborativa y responsabilidades } \\
\text { compartidas. }\end{array}$ \\
\hline $\begin{array}{llr}\text { 5.-Reconocimiento } & \text { de } & \text { la } \\
\text { rendición de cuentas } & \text { o } \\
\text { accountability no es fácil } & \end{array}$ & $\begin{array}{l}\text { Los funcionarios públicos en su labor están } \\
\text { condicionados por las leyes vigentes, tanto a nivel } \\
\text { constitucional como administrativas, por los valores } \\
\text { comunitarios, por los intereses ciudadanos y por los } \\
\text { estándares de exigencia en la labor. }\end{array}$ \\
\hline 6.- Servir en lugar de dirigir & $\begin{array}{l}\text { Los funcionarios sirven como facilitadores del } \\
\text { proceso de expresión y satisfacción de necesidades } \\
\text { colectivas. }\end{array}$ \\
\hline $\begin{array}{l}\text { 7.- Poner en valor a las personas, } \\
\text { no solo a la productividad }\end{array}$ & $\begin{array}{l}\text { Los organismos públicos tienen más probabilidades } \\
\text { de éxito en la medida en que desarrollen redes } \\
\text { colaborativas de apoyo y compromiso. }\end{array}$ \\
\hline
\end{tabular}

Fuente: Elaboración propia a partir de lo planteado por Denhardt y Denhardt (2000, 2003, 2011), citado por Pereira y Jaraíz (2015).

El pensar el servicio público bajo este nuevo paradigma nos lleva a replantear la concepción de ciudadanía. Esta muchas veces es entendida en un proceso meramente delimitado a los preceptos de una democracia representativa. La articulación de una nueva relación con la comunidad surge en primera instancia desde el interior de las municipalidades con directivos empoderados de su quehacer y con una visión del trabajo colectivo que potencia el capital social que representan sus funcionarios.

\section{Método}

El presente artículo, recoge los principales resultados de investigación que tenía como propósito determinar limitantes, desafíos y oportunidades en la construcción de un equipo directivo municipal eficaz, para asegurar la solución de los problemas de su comunidad local, desde la perspectiva orgánica interna municipal de la Municipalidad de Chillán. Para lo anterior, se desarrolló una investigación de tipo cualitativa, El estudio utilizó como técnica principal de recogida de información la entrevista semiestructurada, la que fue aplicada a los directivos de la municipalidad de Chillán, a las alcaldesas de Providencia y Peñalolén y expertos del mundo académico y de la administración pública. Una segunda técnica fue un focus group trabajada con el equipo directivo, con el objeto de reforzar conceptos claves asociados a las categorías del estudio. Finalmente se desarrolló análisis documentación sobre expedientes internos de la Municipalidad, reglamento de funcionamiento interno, revisión de página web municipal y Estatuto Administrativo de los 
funcionarios municipales. El plan de análisis consideró un proceso de triangulación de fuentes de información en base a categorías previamente definidas por los autores.

\section{Resultados}

Basado en revisión documental sobre los enfoques post-burocráticos de administración pública como también de desarrollo territorial, gobierno comunal, y administración municipal, en el presente apartado presentamos las características identificadas en la literatura para equipos directivos eficaces, precisando en primer lugar la definición del concepto que responde a elaboración propia trabajada en base a insumos recogidos durante el proceso investigativo.

Un directivo eficaz es aquel que desarrolla competencias y capacidades en tres áreas interrelacionadas que aseguran un trabajo hacia la comunidad con valor público. Gestión estratégica, política y operativa (Rogers y Guzmán, 2015). Estas áreas deben estar cohesionadas en el actuar del directivo, generando valor al trabajo y propiciando una cultura organizacional y cultural acorde a principios éticos y valóricos.

Esto genera conductas proactivas al cumplimiento de objetivos propiciando espacios de discusión y deliberación permanentes entre sus funcionarios. Opera sobre premisas de creatividad e innovación y arriesga, consensuadamente con sus equipos, nuevas formas de hacer las cosas.

Un directivo eficaz, enfoca su acción al trabajo mancomunado de sus dirigidos y propicia un liderazgo de tipo distribuido que permita democratizar el poder y la participación de los funcionarios en el proceso de toma de decisiones. Se basa en las competencias y debilidades internas de la organización, anticipa cambios en el entorno y las movidas contingentes de oponentes inteligentes. Ordena y asigna los recursos de la organización en una posición única y que sea viable. Las decisiones estratégicas pueden consistir en un ajuste mediante el cual se intenta encontrar la forma de adecuar las actividades de la organización al entorno en el cual opera. Ambos modelos precisan el estudio de unos de los conceptos claves del estudio que nos dan cuenta de una nueva concepción en la cultura organizacional municipal: Capital social interno.

Para entender conceptualmente lo referido a capital social interno, nos basaremos en lo planteado por el autor argentino Jorge Etkin (2007) el cual plantea, para la configuración de este concepto, una serie de cualidades internas que la organización debe tener las que se mencionan a continuación.

En el ámbito de las organizaciones, de acuerdo a este autor, el capital social es una capacidad de crecer y construir, sostenida en los siguientes valores organizacionales: a) El compromiso y la orientación de los integrantes hacia los objetivos de bienestar general más allá de los intereses egoístas o de los fines sectarios; b) La existencia de actitudes cooperativas y solidarias entre los miembros de la organización como forma de alcanzar proyectos también compartidos; c) El comportamiento basado en principios éticos; d) el respeto por las formas democráticas de gestión y la equidad en la apropiación de los 
recursos que dispone y genera la organización, y e) La responsabilidad social por las decisiones de política, considerando sus efectos sobre la sociedad civil. (Etkin 2007: 95).

A partir del análisis de los datos recolectados por nuestra investigación, la siguiente tabla presenta los principales limitantes, desafíos y oportunidades para construir un equipo directivo eficaz. Abstrayendo del estudio de caso, proponemos propuestas que son aplicables para los municipios chilenos en general.

Tabla 3: Limitantes, desafíos y oportunidades en la construcción de un equipo directivo eficaz

\begin{tabular}{|c|c|c|}
\hline Limitantes & Desafíos & Oportunidades \\
\hline $\begin{array}{l}\text { Inexistencia de modelos de } \\
\text { gestión y/o conducción } \\
\text { municipal }\end{array}$ & $\begin{array}{l}\text { Generación de alianzas entre } \\
\text { la Asociación Chilena de } \\
\text { Municipalidades y la } \\
\text { Dirección del Servicio Civil a } \\
\text { objeto de lograr instalar la } \\
\text { lógica del mérito en el } \\
\text { ingreso al servicio municipal } \\
\text { y la profesionalización y/o } \\
\text { capacitación de los alcaldes }\end{array}$ & $\begin{array}{l}\text { Directivos profesionales de } \\
\text { carrera funcionaria }\end{array}$ \\
\hline Escaso trabajo en equipo & $\begin{array}{l}\text { Generar buenas prácticas que } \\
\text { permitan mejorar niveles de } \\
\text { coordinación y comunicación } \\
\text { entre unidades. } \\
\text { Visualizar en el trabajo } \\
\text { colaborativo una estrategia de } \\
\text { mejora continua de procesos } \\
\text { internos }\end{array}$ & $\begin{array}{l}\text { Voluntad de directivos de } \\
\text { trabajar colaborativamente } \\
\text { en ambientes más } \\
\text { democráticos }\end{array}$ \\
\hline $\begin{array}{l}\text { Carencia de liderazgos } \\
\text { directivos }\end{array}$ & $\begin{array}{l}\text { Democratizar el proceso de } \\
\text { toma de decisiones a través } \\
\text { de socialización de liderazgos } \\
\text { distribuidos }\end{array}$ & $\begin{array}{l}\text { Directivos con experiencia y } \\
\text { experticia en las } \\
\text { municipalidades }\end{array}$ \\
\hline $\begin{array}{l}\text { Deficiente capacitación } \\
\text { funcionaria }\end{array}$ & $\begin{array}{l}\text { Generación de reglamento de } \\
\text { capacitación funcionaria por } \\
\text { estamentos que incorpore } \\
\text { limitantes diagnosticada. }\end{array}$ & $\begin{array}{l}\text { Existencia de la academia de } \\
\text { formación y capacitación } \\
\text { funcionaria de la SUBDERE }\end{array}$ \\
\hline $\begin{array}{l}\text { Inadecuada organización } \\
\text { del trabajo: cultura } \\
\text { organizacional }\end{array}$ & $\begin{array}{l}\text { Implementación adecuada al } \\
\text { espíritu de la ley } 20922 \text { de } \\
\text { plantas municipales } \\
\text { (Profesionalización de la }\end{array}$ & $\begin{array}{l}\text { Ley } 20922 \text { de Plantas } \\
\text { Municipales }\end{array}$ \\
\hline
\end{tabular}




\begin{tabular}{|c|c|c|}
\hline & acción municipal) & \\
\hline $\begin{array}{l}\text { Desconocimiento por parte } \\
\text { de directivos y funcionarios } \\
\text { de los instrumentos de } \\
\text { planificación de la comuna: } \\
\text { PLADECO, plan regulador, } \\
\text { presupuesto municipal. }\end{array}$ & $\begin{array}{l}\text { Generación de instrumentos } \\
\text { de planificación territorial } \\
\text { con enfoque participativo: } \\
\text { nivel directivo-comunidad }\end{array}$ & $\begin{array}{l}\text { Profesionales de carrera } \\
\text { capacitados en temáticas } \\
\text { afines. }\end{array}$ \\
\hline $\begin{array}{l}\text { Inexistencia de política de } \\
\text { recursos humanos }\end{array}$ & $\begin{array}{l}\text { Generación de la política de } \\
\text { recursos humanos que defina } \\
\text { perfiles de ingreso a la } \\
\text { administración municipal }\end{array}$ & $\begin{array}{l}\text { Existencia del comité } \\
\text { bipartito en todas las } \\
\text { municipalidades } \\
\text { conformados por } \\
\text { representantes de los } \\
\text { funcionarios y de las } \\
\text { administraciones. }\end{array}$ \\
\hline $\begin{array}{l}\text { Precarios niveles de } \\
\text { exigencia de los } \\
\text { funcionarios municipales en } \\
\text { el cumplimiento de los } \\
\text { planes de mejoramiento de } \\
\text { la gestión (metas } \\
\text { Institucionales y colectivas) }\end{array}$ & $\begin{array}{l}\text { Nuevas exigencias de } \\
\text { Subsecretaria de Desarrollo } \\
\text { Regional para presentación de } \\
\text { los planes de mejoramientos } \\
\text { de la gestión (PMG) }\end{array}$ & $\begin{array}{l}\text { Existencia de Comités de } \\
\text { Gestión de metas colectivas } \\
\text { e institucionales por } \\
\text { unidades en todas las } \\
\text { municipalidades del país } \\
\text { que deben definir } \\
\text { adecuadamente dichas } \\
\text { metas. }\end{array}$ \\
\hline
\end{tabular}

Fuente: Elaboración propia a raíz de análisis categorías de estudios.

Integrado el marco teórico y respondiendo a las conclusiones diagnósticas del equipo directivo municipal asociadas a las limitantes, desafíos y oportunidades, planteamos las siguientes propuestas, que podrán ser consideradas como insumos para el Municipio de Chillán al objeto de aportar en la mejora de sus procesos de trabajo.

Durante el proceso de entrevistas al equipo directivo de la municipalidad de Chillan, se plantean una serie de limitantes a la gestión directiva, tales como débil identificación de liderazgos, escaso trabajo en equipo, inexistencia de equipos técnicos de gestión y/o de asesorías, rotación de profesionales en direcciones claves de trabajo hacia la comunidad.

En base a lo anterior, y considerando los elementos conceptuales respecto a Equipos Directivos Eficaces, planteamos como estrategias principales las siguientes:

a) La Creación de la Dirección de Recursos Humanos: Es una de las grandes apuestas de la nueva ley de plantas municipales que pasará a integrar el cuarto elemento de planificación de las municipalidades. La incorporación de una nueva Dirección al organigrama municipal responde a las demandas de los propios funcionarios municipales, quienes representados por su dirigencia gremial ASEMUCH, lograron que desde el ejecutivo y a nivel nacional se visualizara en los funcionarios el capital social interno necesario de considerar como eje 
clave en cualquier gestión municipal. Definir las condiciones del ingreso, estadía y desarrollo funcionario y de egreso de los funcionarios a la administración pública permitirá perfilar un mejor recurso humano, más capacitado y con perfiles acordes a las demandas de cada comuna.

La unidad de recursos humanos establecida en la ley deberá tener las siguientes áreas de gestión: Gestión del Desempeño Funcionario, Gestión del Desarrollo Profesional, y Gestión del Cambio Organizacional en cada municipio.

De esta forma, será posible mejorar los procesos y procedimientos de trabajo de los funcionarios municipales, contribuyendo de manera más decisiva en la solución de los problemas planteados de orgánica interna y como consecuencia en los procesos de trabajo hacia la comunidad.

- La creación de un Comité de Gestión: Este comité debiera ser conformado por la unidad de recurso humano y su principal tarea será generar un modelo de conducción y coordinación directiva que favorezca sinergia y colaboración en el trabajo interno. Este comité, asegurará periodicidad y constancia en el trabajo colectivo, en la resolución de tareas internas de manera eficiente y eficaz, además de generar iniciativas de capacitación permanente del cuerpo directivo profesional del municipio, que permita atender las principales debilidades detectadas.

- Se propone que este equipo de gestión elabore un reglamento de ingreso a la administración municipal, que regule los llamados a concursos públicos, con exigencias de tipo técnicas, de experiencia y trayectoria y que incluya estas exigencias a los cargos de confianza de la autoridad. De esta forma se compatibilizará perfiles técnicos académicos con la variable política a la cual están sometidos los ambientes municipales en cada periodo alcaldicio. Así lo ha demostrado un estudio realizado por académicos del Banco Interamericano de Desarrollo (BID) quienes concluyeron que el ingreso de directivos públicos seleccionados por mérito habría traído una serie de mejoras en la gestión interna de las organizaciones y en sus prácticas de trabajo (productos u outputs) más que en los resultados (outcomes). En términos de su llegada a las Instituciones, adquieren entre los funcionarios de una mayor legitimidad, lo que genera un positivo ingreso a los equipos de trabajo.

- Esta generación de iniciativas deberá estar contemplada en un reglamento de capacitación, que deberá ser elaborado por los directivos integrantes del comité y que procurará integrar a todos los estamentos municipales, potenciando recursos disponibles (oportunidades) y reforzando áreas deficitarias (debilidades). Las áreas de fortalecimiento interno, según temáticas, se enfocarán en: liderazgo directivo, trabajo en equipo, elaboración de indicadores de evaluación, definición de estrategias de intervención, modelos de trabajo, desarrollo organizacional y gestión estratégica.

- Una debilidad diagnosticada en el municipio de Chillán dio cuenta de la alta rotación de profesionales en unidades claves de la relación municipio-comunidad y que responden a 
decisiones de la primera autoridad. Se evidencia una debilidad de conducción para consolidar equipos directivos de exclusiva confianza. En este aspecto se hace necesario considerar una mejor definición de perfiles, competencias técnicas y académicas de estos cargos directivos de exclusiva confianza del alcalde.

b) Pensamos que es posible dirigir los principios de la nueva gestión pública (NGP) que desarrolla la Dirección del Servicio Civil del país hacia las municipalidades, a través de la generación de un convenio de colaboración y transferencia técnica entre la Asociación Chilena de Municipalidades y el Servicio Civil que permita por ejemplo, capacitar profesionalmente a los alcaldes recientemente electos en materias como liderazgo directivo, técnicas de manejo de equipos de trabajo, así como técnicas en motivación de su personal, generación de dinámicas de acción colectiva que vayan en beneficio de sus funcionarios y de las políticas locales. Alcaldes capacitados para el liderazgo directivo, más equipos directivos de profesionales y técnicos con experiencia y administrativos empoderados y motivados dan el camino del éxito de una gestión local decisiva. La Misión del Servicio Civil de fortalecer la función pública y contribuir a la modernización del Estado a través de la implementación de políticas de gestión y desarrollo de las personas y altos directivos para promover un mejor empleo y un Estado al servicio de las personas, son objetivos concordantes con los que persiguen las municipalidades, en materia de gestión pública y de gestión de personas, por lo que los mecanismos de trabajo de esta institucionalidad podrían pensarse en un futuro próximo para ser incorporado al ámbito y quehacer municipal.

\section{Conclusiones}

Cambios económicos, sociales y demográficos en los últimos 25 años de nuestro país han provocado transformaciones relevantes en el Estado Nacional. La modernización del Estado Chileno se hace imprescindible y es observable en todas las esferas de la vida pública institucional.

Los servicios públicos nacionales, regionales, provinciales y comunales se demuestran más eficientes en el cumplimiento de sus metas al servicio de la sociedad. Incorporan cada vez más tecnología digital. La ciudadanía accede a ellos con mayor rapidez y con mejores resultados. Los municipios en cuantos servicios públicos locales, del mismo modo, se suman a esta tendencia de más y mejor desarrollo institucional al servicio de sus habitantes. De la mera administración local han avanzado cada vez más y mejor a actuar como un verdadero gobierno comunal, capaz de hacer frente a las demandas de su ciudadanía, sin esperar que las soluciones provengan de la administración central o regional.

Las municipalidades requieren directivos públicos profesionales capacitados, eficaces y eficientes, comprometidos con su comunidad local. Ellos son los llamados a impulsar y desarrollar políticas de gobierno para la vida social, económica y cultural de sus habitantes. Alcaldes y Concejos Municipales, directivos y funcionarios municipales son todos agentes activos comprometidos con un gobierno comunal dinámico y perseverante en el cumplimiento de sus propósitos. Esta es la clave del éxito de un gobierno comunal comprometido con su pueblo. 
Esta realidad es similar en todo el país. No obstante, es importante detenernos en aquellos municipios más pequeños y alejados del radio urbano en los cuales, la priorización de sus problemas pasa por situaciones tangibles que son parte de su cotidianeidad y que requieren movilización inmediata de recursos, tales como accesibilidad, acercamiento de tecnologías, capacidad técnica para postular a proyectos, entre otros. Las energías profesionales y oportunidades de mejora están determinadas por sus realidades que conviven con variables económicas y geográficas. Se requiere mayor atención y apoyo hacia ellos.

La nueva gestión pública y sus principios: profesionalismo y proactividad, énfasis en la satisfacción de sus usuarios, descentralización de sus unidades, con disciplina y control de los recursos públicos, posibilitarán servir a sus ciudadanos con mayor eficiencia. Pensando y actuando de manera democrática y transparente, asegurando la participación y el compromiso activo de todos los funcionarios municipales y de su propia comunidad local, lograra alcanzar las metas trazadas con pleno éxito.

El desarrollo territorial de Chile a pesar de los grandes avances que hemos destacado continúa atado a un centralismo excesivo que domina al Estado Nacional. Se hace imprescindible descentralizar cada vez más las políticas públicas hacia territorios más acotados geográficamente, como lo son las regiones del país, sus provincias y sus comunas, dotándolos de mayor autonomía y asegurando un mejor y más eficiente control público de los recursos que se les encarga administrar con mayor eficiencia. Esta es la demanda nacional de mayor impacto en el chile de hoy.

Numerosas trabas y dificultades legales imposibilitan a los municipios para resolver por sí mismos determinadas acciones o iniciativas de bien común dirigidas a sus comunidades locales. Los directivos entrevistados, en una crítica y objetiva reflexión, reconocen que nuestro país requiere mayores y mejores autonomías para las municipalidades, que les permitan actuar como verdaderos gobiernos comunales, con plenos poderes institucionales.

La reciente Ley $\mathrm{N}^{\circ} 20.922$ sobre profesionalización de la acción municipal conocido como Ley de Plantas Municipales, representa un avance en autonomía de los municipios para que éstos definan sus propias plantas de funcionarios de acuerdo a sus realidades. Asimismo, se obliga a la creación de la Dirección de Recursos Humanos que tiene como eje central la gestión de personas al alero de una adecuada política de personal. Se reconoce en los funcionarios, el capital social interno que se traduce en uno de los principales insumos para crear sinergia, colaboración y trabajo en equipo.

Un equipo directivo eficaz se caracteriza por el esfuerzo colectivo desplegado en el cumplimiento de los objetivos y tareas institucionales. Tareas que se derivan de las metas institucionales plasmadas en los instrumentos de planificación municipal: PLADECO, Plan Regulador, Presupuesto Municipal. El conocimiento de estos instrumentos y la socialización de ellos al interior del cuerpo directivo, esbozados como carta de navegación en la gestión municipal, configuran un escenario deseable de trabajo productivo al interior del municipio y como consecuencia de esto, en su relación de trabajo con la comunidad. 
Los principios de la Nueva Gestión Pública consideran al mérito, la profesionalización, la especialización del trabajo, el nuevo trato hacia el público usuario y la modernización de los servicios, como ejes centrales de la administración del Estado. Estos principios se conectan estrechamente con las características de un equipo directivo eficaz en tanto considera, por parte de los entrevistados del estudio de caso, la preparación académica, el mérito en el cargo y la experticia que el conocimiento y la experiencia otorgan al desarrollar cargos claves de la gestión municipal.

Tal como se señala en Rogers y Guzmán (2015) "Se crea valor público cuando se atiende eficaz y consistentemente las demandas de la ciudadanía" (Rogers y Guzmán, 2015:49) considerando en esta afirmación la generación de valor público que además de ser una de las finalidades del Estado, busca un equilibrio virtuoso entre la eficacia y la legitimidad. Esa debe ser la tarea principal de un equipo directivo municipal

El trabajo en equipo genera interdependencia entre funcionarios y el entorno, se establecen canales de comunicación entre directivos y funcionarios, que se mueven en un marco regulatorio Institucional. Así lo plantea Paul Cilliens, (1998), citado por Waissbluth (2008) en una de las 10 características centrales de los sistemas complejos "Las interacciones entre las partes tienen retroalimentación (feedbackloops) una actividad recibe efectos sobre sí misma, a través de amplificaciones o inhibiciones, y pueden ocurrir directamente o a través de circuitos indirectos. A esto se le llama recurrencia" (Cilliens, 1998, citado en Waissbluth, 2008:06).

En relación al análisis anterior, y luego de estudiar las estadísticas gráficas de la planta municipal, podemos afirmar que la municipalidad de Chillán está haciendo uso de su capacidad funcionaria de planta sólo en un $70.83 \%$, dejando un porcentaje importante de vacantes de todo nivel, profesionales, técnicos, administrativos, que, si fueran cubiertos, resolvería gran parte de la falta de personal municipal con responsabilidad administrativa. Se evidencia muy claramente un problema de gestión en esta materia. Tal como lo menciona nuestro entrevistado Sr. Ricardo Cifuentes, Subsecretario de Desarrollo Regional "para que el municipio pase de administración local a gobierno local, pasa por preocuparse primero, del recurso humano" lo que nos da cuenta de la importancia de apostar en su cuerpo de profesionales y funcionarios en general como capital humano que será el responsable de generar cambios en las estructuras de trabajo y en la forma como se concibe este nuevo enfoque de trabajo municipal. 


\section{Referencias}

Aguilar Villanueva, L. (2007). El aporte de la política pública y de la nueva gestión pública a la gobernanza. Revista de CLAD Reforma y Democracia, (39), 5-32. https://www.redalyc.org/pdf/3575/357533693001.pdf

Aguilar Villanueva, L. (2010). Gobernanza, el nuevo proceso de gobernar. Fundación Friedrich Naumann para la Libertad.

Ander-Egg, E. (1995). Técnicas de investigación social. Lumen.

Barreiro, F. (1998). Los agentes del desarrollo. Centro Latinoamericano de Economía Humana.

Boisier, S. (1983). Un difícil equilibrio. Descentralización y centralización en la planificación regional. Estudios de Economía, 5(1), 67-85. https://www.repository.utl.pt/bitstream/10400.5/9723/1/ee-sb-1984.pdf

Boisier, S. (2001). Desarrollo (local): ¿De qué estamos hablando?. Municipios Universidad Nacional de Quilmes. http://municipios.unq.edu.ar/modules/mislibros/archivos/29-DesLo.pdf

Boisier, S. (2002). El Estado del arte del desarrollo descentrado y en América Latina.

Boisier, S. (2009). Sinergia e innovación local. Semestre Económico, 12(24), 21-35. http://www.scielo.org.co/scielo.php?pid=S0120-

$63462009000200002 \&$ script $=$ sci_abstract\&tlng=es

Cádiz, V. (2005). Las transformaciones del Estado de Chile a fines del siglo XX. La Critica. https://critica.cl/ciencias-sociales/las-transformaciones-del-estado-en-chile-a-finesdel-siglo-xx

Capella, H. (2002). Geografía cultural, la gran desconocida. Boletín de la AGE. 34, 11-18. http://bibliotecadigital.academia.cl/xmlui/bitstream/handle/123456789/588/Hugo\%20Capel la.pdf?sequence $=1 \&$ is Allowed $=y$

Capella, H. (2009). Por los caminos de la identidad y del desarrollo regional. Atenea 500, 75-90. http://dx.doi.org/10.4067/S0718-04622009000200006

Cilliers, Pau (1998). Complexy and postmodernism. Routledge. https://doi.org/10.4324/9780203012253

Comisión Asesora Presidencial en Descentralización y Desarrollo Regional (2014). Propuesta de política de Estado y agenda para la descentralización y desarrollo territorial en Chile. Prensa Presidencia. https://prensa.presidencia.cl//fi-content/otras/informescomisiones/InformeDescentralizacion.pdf

Cunill, N. (2009). La modernización de la gestión pública en Chile y su impacto en el proceso de descentralización. Facultad Latinoamericana de Ciencias Sociales Chile. https://www2.congreso.gob.pe/sicr/cendocbib/con3_uibd.nsf/8F79160F42E2F0880525786 A006616F6/\$FILE/moder_gestion_publi_chile.pdf

Cunill, N. (2011). La democratización de la administración pública. Los mitos a vencer. Congreso Gobierno de Perú. https://www2.congreso.gob.pe/sicr/cendocbib/con3_uibd.nsf/8F79160F42E2F0880525786 A006616F6/\$FILE/moder_gestion_publi_chile.pdf 
Denhardt, R.B. y Denhardt, J.V. (2000). The new public service: serving rather than sterring. Public Administration Review, 60(6), 549-590.

Doña, K. (2006). Síntesis del proceso de modernización del Estado en Chile (1994-2003). Documentos de Apoyo Docente. http://biblioteca.esucomex.cl/RCA/S\%C3\%ADntesis\%20del\%20proceso\%20de\%20moder nizaci\%C3\%B3n\%20del\%20Estado\%20en\%20Chile.pdf

Drucker, P. (1986). Management. Tasks, responsibilities, practices [Tareas, responsabilidades, practices]. Truman Talley Books. http://ipwna.ir/wpcontent/uploads/2018/05/Management-Tasks-Responsibilities-Practices-by-Peter-Druckerirpublicpolicy.pdf

Escobar, J. y Bonilla, F. (2017). Grupos focales. Una guía conceptual y metodológica. Cuadernos hispanoamericanos de psicología, 9(1), 51-67. http://www.tutoria.unam.mx/sitetutoria/ayuda/gfocal-03122015.pdf

Etkin, J. (2007). Capital social y valores en la organización sustentable. Ediciones Granica.

Fayol, H. (1979). Administración industrial y general. Editorial Ateneo.

Gattini, C. y Álvarez, J. (2011). La salud en Chile 2010. Panorama de la situación de salud y del sistema de salud en Chile. Oficina de la Representación OPS/OMS en Chile Organización Panamericana de Salud. https://www.paho.org/chi/dmdocuments/salud\%20chile\%202010.pdf

Guerrero, O. (1997). Principios de la administración pública. Escuela Superior de Administración Pública Colombia.

Servicio Civil (2015). Instructivo Presidencial sobre las Buenas Prácticas Laborales. Servicio Civil. http://www.oas.org/juridico/PDFs/mesicic5_cl_res_civ_ane9.pdf

Longo, F. (2008). Liderazgo distribuido, un elemento crítico para promover la innovación. Capital Humano, 226, 84-91.

Mariñez, F. (2013). La gestión del nuevo servicio público. XVIII Congreso Internacional del CLAD sobre la Reforma del Estado y de la Administración Pública. http://www.freddymarinez.com/docs/marinez.pdf

Morlino, L. (1996). Las democracias. Manual de Ciencia Política. Editorial Alianza.

Pardo, M. (2004). De la administración pública a la gobernanza. Centro de Estudios Internacionales.

Pereira, M. y Jaráiz, E. (2015). El nuevo servicio público (NSP), un paradigma para la construcción de nuevos modelos metodológicos para el análisis de la administración pública. Revista de Investigaciones Políticas y Sociológicas, 14(2), 73- 93. https://www.redalyc.org/pdf/380/38043460003.pdf

Ramírez, A. (2001). Reforma del Estado, modernización de lagestión pública y construcción de capital social. El caso chileno (1994-2001). Departamento de Ingeniería Industrial, Universidad de Chile. http://www.dii.uchile.cl/ ceges/publicaciones/ceges32.pdf Rogers, R. y Guzmán, N. (2015). El directivo público hoy. Contexto, roles y desafíos. Servicio

Civil.

https://www.serviciocivil.cl/wpcontent/uploads/2017/06/directivo_publico_hoy_final.pdf 
Ruiz Olabuenaga, J. (1996). Metodología de la investigación cualitativa. Editorial Bilbao. Sampieri, R.; Fernández-Collado, C. y Baptista, P. (2006). Metodología de la investigación. Mc Graw-Hill Interamericana Editores.

Sanabria, M. (2007). De los conceptos de administración, gobierno, gerencia, gestión y management: Algunos elementos de corte epistemológico y aportes para una mayor comprensión. Universidad $\quad y \quad$ Empresa, https://revistas.urosario.edu.co/index.php/empresa/article/view/1040/939

Spillane, J. P.; Halverson, R. y Diamon, J. B. (2001). Investigating school leadership practice: A distributed perspective. Educational Researcher, 30(3), 23-28. https://doi.org/10.3102/0013189X030003023

Taylor, F. (1911). Principios de la administración científica. Editorial Ateneo, Tomassini, L. y Armijo, M. (2002). Reforma y modernización del Estado. Experiencias y desafios. Lom Ediciones - Universidad de Chile.

Uroz, J. (2010). La llamada crisis del modelo de Estado de Bienestar: Reestructuración y alternativas. $\quad$ Miscelánea Comillas, 68(132), 299-311. https://revistas.comillas.edu/index.php/miscelaneacomillas/article/view/840/709

Uvalle, R. (2009). Condiciones, procesos y tendencias de la administración pública $\begin{array}{llll}\text { contemporánea. } & \text { Convergencia, } & \text { 76(49), } & \text { 73-102. }\end{array}$ http://www.scielo.org.mx/scielo.php?script=sci_arttext\&pid=S1405-14352009000100004 